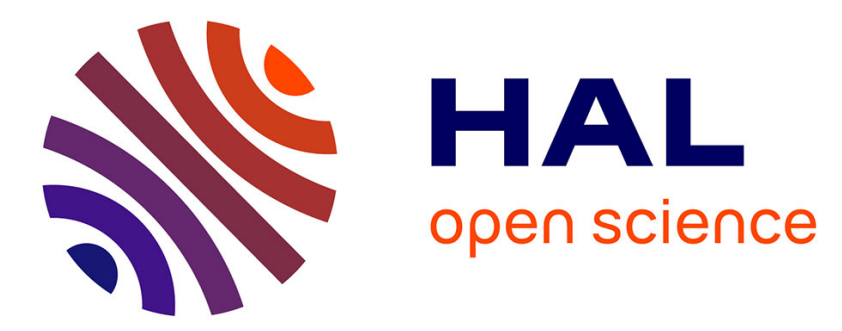

\title{
Thermodynamic investigation on an innovative unglazed transpired solar collector
}

\author{
Cristiana V. Croitoru, Ilinca Nastase, Florin I. Bode, Amina Meslem
}

\section{To cite this version:}

Cristiana V. Croitoru, Ilinca Nastase, Florin I. Bode, Amina Meslem. Thermodynamic investigation on an innovative unglazed transpired solar collector. Solar Energy, 2016, 131, pp.21-29. 10.1016/j.solener.2016.02.029 . hal-01302339

HAL Id: hal-01302339

https://hal-univ-rennes1.archives-ouvertes.fr/hal-01302339

Submitted on 26 May 2016

HAL is a multi-disciplinary open access archive for the deposit and dissemination of scientific research documents, whether they are published or not. The documents may come from teaching and research institutions in France or abroad, or from public or private research centers.
L'archive ouverte pluridisciplinaire HAL, est destinée au dépôt et à la diffusion de documents scientifiques de niveau recherche, publiés ou non, émanant des établissements d'enseignement et de recherche français ou étrangers, des laboratoires publics ou privés. 


\section{THERMODYNAMIC INVESTIGATION ON AN INNOVATIVE UNGLAZED TRANSPIRED SOLAR COLLECTOR}

Cristiana V. Croitoru ${ }^{\text {a, b }}$, Ilinca Nastase ${ }^{\mathrm{a}}$, Florin I. Bode ${ }^{\mathrm{c}, \mathrm{a}}$, Amina Meslem ${ }^{\mathrm{d}}$

${ }^{\text {a }}$ CAMBI Research Centre, Faculty of Building Services Engineering, Technical University of Civil Engineering in Bucharest, Romania

${ }^{\mathrm{b}}$ Faculty of Mechanical Engineering, Politehnica University Bucharest, Romania

${ }^{c}$ Mechanical Engineering Department, Technical University of Cluj-Napoca, Romania

d LGCGM EA3913, Equipe Matériaux et Thermo-Rhéologie, Université Rennes 1, 3 rue du Clos Courtel, BP 90422, Rennes Cedex 7, France

Keywords: unglazed transpired solar walls, ventilated facade, energy saving

\section{SUMMARY}

Renewable energy represents an attractive solution to fulfil two requirements: indoor air quality and energy efficiency. Passive solar systems are easy to implement and effective in areas with high solar potential. The Unglazed Transpired Solar Wall (UTSW) is made of metal cladding with perforations, installed at several centimetres from a building wall, creating thus a cavity, allowing to preheat the fresh air. Several measurements were performed on an innovative perforated solar wall model. This study is a preliminary approach of an analysis on the importance of the orifice shape of the perforated panel as a heat transfer influencing parameter. Both the fluid dynamics and thermal behaviours were investigated. The more complex dynamics of the lobed flows results in a better heat transfer rate. Changing the geometry of the perforations will increase on one hand the orifice's perimeter and it would generate complex fluid dynamics, resulting in higher mixing between the primary flow 
and the ambient and thus a higher efficiency of heat recovery of these devices. The comparison of a conventional UTSW with a new geometry with innovative perforation leads to interesting results, with almost $40 \%$ increase in thermal efficiency.

\section{INTRODUCTION}

The building sector remains an important player on the international economy dynamics, at it integrates significant resources which can be translated in energy consumption. In this context, European Directives (Directive on the energy performance of buildings 2002/91/EC) require, for example, a high energy performance of buildings for significant reduction of the energy consumption (Energy 2002). Different countries have already adopted drastic regulations in order to achieve high building performance. In the same time, the environmental quality is an important parameter requested for residential or tertiary buildings.

Indoor air quality and energy consumption go hand in hand in urban environment which is developing faster in the latest decades. Buildings are the largest energy consuming sector in the world, and account for over one-third of total final energy consumption and an equally important source of carbon dioxide (CO2) emissions (IEA 2013). Given that many nations are actively pursuing carbon reduction plans, achieving significant energy and emissions reduction in the buildings sector is a challenging but achievable policy goal. The built environment offers also some opportunities to save energy through the use of innovative systems or through advanced management systems (Kumar and Morawska 2013).

In the same time indoor air quality has become a critical parameter when considering health of the occupants and the importance of fresh air inside buildings. Further complexity is added by the changing climatic conditions and the human expectations of comfortable indoor 
environments, both of which increase building energy requirements for heating, cooling or lighting. Local climate conditions directly influence the energy consumption of buildings through HVAC systems, whether there is a heating or a cooling load. During the cold season in cold countries, the heat demand of the building represents the highest percentage from the total amount of energy demand, while during the summer, air treatment or ventilation is a major consumer of electrical energy. For example, in United Kingdom, the energy used for interior heat demand was about 50\% of the total energy consumption in 2004 (UNEP 2007). On the other hand, air cooling systems use more than $40 \%$ of peak load in a hot summer in Shanghai(Al-Shaalan 2012). All these energy consumptions, whether it's heating or cooling demand, can be translated in terms of $\mathrm{CO}_{2}$ emissions (IEA 2007, IEA 2007, IEA 2008). The renewable sources can provide low-cost energy consumption when using passive systems. Among these renewable energies, the use solar systems are easy to implement and efficient from the accessibility point of view in the zones with solar potential (IEA 2005). These systems can have a significant contribution to achieve high envelope performances and in the same time to save energy for winter heating or/and summer cooling. The multitude of solutions for using thermal energy from the Sun has important advantages but also disadvantages that maintains the research in this area. Among them, thermal walls can be split in several categories (i.e. Trombe walls, solar eutectic walls, other systems that store energy with water) (Hami, Draoui et al. 2012). Solar Air Collectors have some interesting potential benefits (no danger of frost, no health and environmental dangers due to leakages) in comparison to Liquid Heating Collectors (Reichl, Kramer et al. 2015) and are potentially cheaper in acquisition and maintenance. One of the most interesting solution is from our point of view the solar collector walls or Unglazed Transpired Solar Walls (UTSW).

An UTSW is made of metal cladding with perforations, installed at a certain distance from a building wall, thus creating a cavity through which the air is circulating. The metal cladding 
is heated by the solar radiation from the sun and ventilation fans create negative pressure in the cavity, extracting the solar heated air through the perforated panel. The air is generally taken off at the top of the wall (due to air temperature gradients in the cavity) ensuring that all of the produced solar heat is collected and then distributed in the building via the ventilation system. The heat transfer between the fluid and the metal is intensified depending on the flow's characteristics and other external parameters.

A quick survey allows us to be aware of the huge possibilities of such devices in energy recovery. For instance, the CFD study of Arulanadam et al. (Arulanandam, Hollands et al. 1999) concludes that not only metal cladding could be used for the perforated absorber but even low conductivity materials can lead to acceptable thermal efficiency of the system, for low porosity of the transpired plate absorbers and for low velocity flow situations. But studies such as the ones of Van Decker et al. (Van Decker, Hollands et al. 2001), Gunnewieck et al. (Gunnewiek, Brundrett et al. 1996, Gunnewiek, Hollands et al. 2002) are very interesting from our point of view, given the information related on the direct possibilities of improvement of these devices. The early numerical study of Gunnewieck et al. (Gunnewiek, Brundrett et al. 1996) highlights the importance of a non-uniform flow and of a low velocity on the efficiency of unglazed transpired solar air heaters of large area. Van Decker et al. (Van Decker, Hollands et al. 2001) show that in no-wind conditions, about $62 \%$ of the ultimate temperature rise of the air is predicted to occur on front-of plate, $28 \%$ in the hole and $10 \%$ on the back of the plate. Cordeau and Barrington (Cordeau and Barrington 2011) in their study of an UTSW used for bringing fresh air in a broiler barn, reveal that the efficiency of the solar air pre-heaters reached $65 \%$ for wind velocities under $2 \mathrm{~m} / \mathrm{s}$, but dropped below $25 \%$ for wind velocities exceeding $7 \mathrm{~m} / \mathrm{s}$, with an annual return on investment of 4.7\%. Different other case studies of UTSW (Hollick 1994, Molineaux, Lachal et al. 1994, Gunnewiek, Brundrett et al. 1996, Hollick 1998, Nábìlek, Kiran et al. 1999, Gunnewiek, Hollands et al. 2002, Sopian, Syahri et al. 2004, Konttinen, Salo et al. 2005, Leon and Kumar 
2007, Belusko, Saman et al. 2008, Kumar and Mullick 2010, Cordeau and Barrington 2011) pointed out an energy efficiency of the system used from $52 \%$ to $68 \%$, being an important benefit in terms of fossil energy consumptions savings.

The literature indicates the interest in using such technologies and implementing a special geometry for the perforations would conduct to a heat transfer increase. The purpose of this article is to prove the efficiency increase of lobed geometries, underlining the benefit of passive solar systems. This special type of perforations can be further implemented in efficient ventilated façades for heating the fresh air introduced in the building.

\section{MATERIALS AND METHODS}

The system exploits solar radiation using collectors that are in the form of panel that can be installed on a wall or on the roof. Schematically, their general configuration is as follows:

At the outer surface of the system we find a metal sheet provided with perforations which are aspirating the air. The metal plate, installed at several centimetres from the building wall, creates a cavity (plenum) for circulating air passing through the perforations (Figure 1). This way, when the metal plate is heated by solar radiation, the air circulating from the bottom is heated along the latter and enters indoor with a ventilation system. A fan is placed on the top of the wall in order to create a negative pressure, forcing the air circulation.

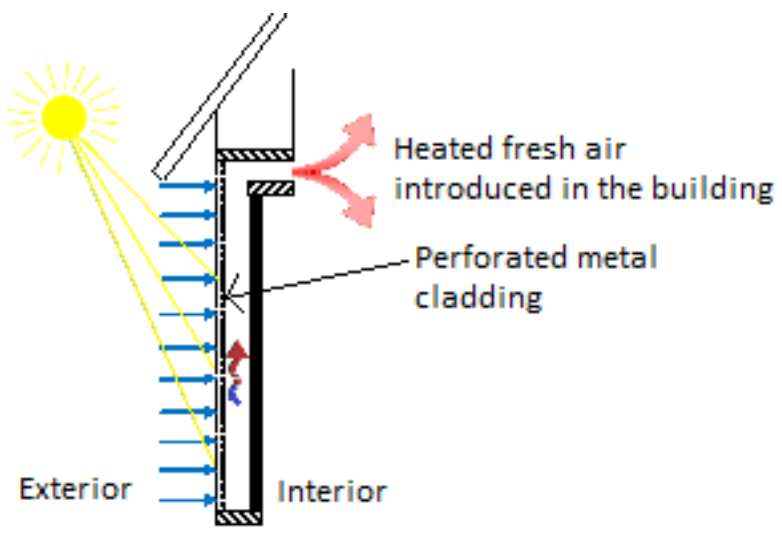

Figure 1: Unglazed transpired solar wall principle: Sun's radiation heats the perforated metal cladding, heat which will be transferred to passing airflow 
Two types of perforations were used for the solar collector: round and cross shape geometry. The purpose is to assess the efficiency of the solar collector with cross perforations. The experimental campaign was conducted in two directions: PIV measurements and visualizations of the flow inside a UTSW model and air temperature measurements when using halide lamps radiation simulating the Sun. Both dynamic and thermal evaluations were meant to properly assess the characteristics for the two cases: round and cross perforation case.

Two different types of perforated claddings were tested, intending to compare the results regarding dynamic and thermal characteristics. The first one is a baseline cladding with classical round perforation (Figure 2a) and the second one is an innovative cladding with lobed cross shaped perforation (Figure $2 b$ ).

The perforated panel models were placed on a rectangular box in Plexiglas, having the dimensions of: $10 \mathrm{~cm} \times 10 \mathrm{~cm} \times 7 \mathrm{~cm}$ (Figure 3). Each perforated cladding has a dimension of $10 \mathrm{~cm} \times 10 \mathrm{~cm}$ with a width of $2 \mathrm{~mm}$. The equivalent diameter $\mathrm{D}_{\mathrm{e}}$ of both geometries of orifices was $5 \mathrm{~mm}$. The degree of porosity for each type of tested perforated panel is given by the distance $\mathrm{S}$ between two adjacent orifices, from centre to centre, of $20 \mathrm{~mm}$ for each type of perforation.
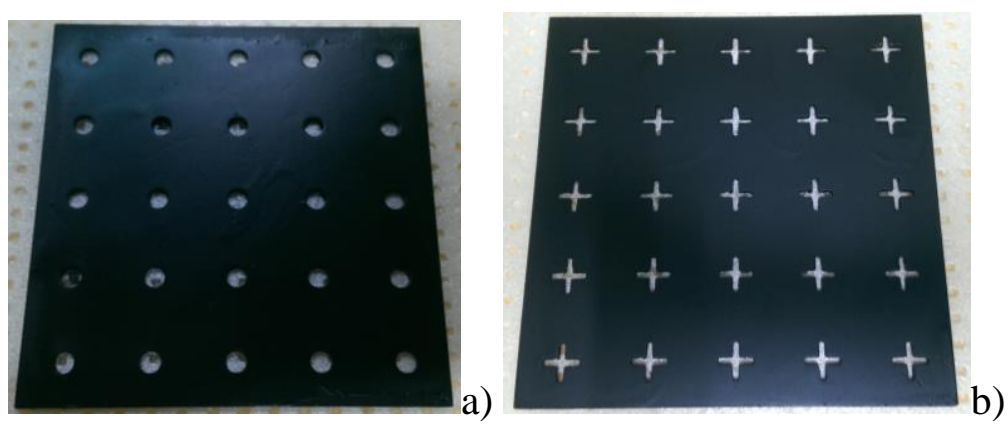

Figure 2: Evaluated perforated claddings: a) Round perforation; b) Lobed cross perforation;

b) 


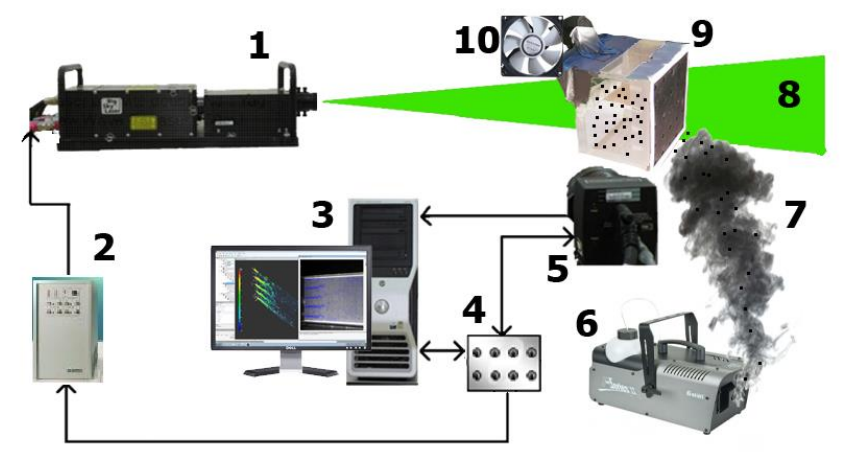

a)

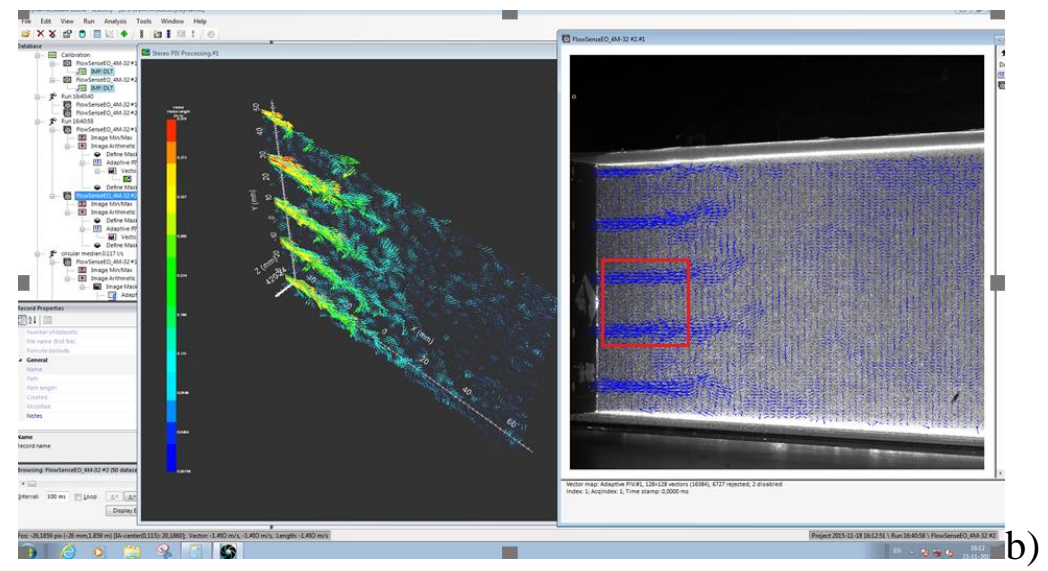

Figure 3: a) Experimental setup for the PIV measurements: 1- two cavities laser; 2- laser chiller; 3- computer; 4- synchronizer; 5- camera; 6- particles generator; 7-seeding particles; 8- laser sheet; 9- inlet perforated cladding; 10- outlet; b) PIV data acquisition software;

The box is connected through a circular pipe to an exhausting fan, forcing the ambient air to pass through the perforated panel. After positioning of each perforated cladding, the box is sealed, in order to have no leaks, which might perturb the tests. The fan is controlled with a DC electrical source, imposing the voltage used. In a first configuration (Reference case) we set up the DC source at $7.091 \mathrm{~V}$, creating $0.61 \mathrm{~m}^{3} / \mathrm{h}$ airflow and a maximum velocity of 0.66 $\mathrm{m} / \mathrm{s}$ measured after the exhaust point in the connected tube (see Figure $4 \mathrm{c}$ ). The same voltage was used for the cross perforated panel, but the maximum velocity obtained was $0.64 \mathrm{~m} / \mathrm{s}$ (Case 1). In order to obtain the same velocity as the initial test at measuring point and thus the same air flow we have increased the voltage to $7.191 \mathrm{~V}$ - Case 2 (See Figure 4). The suction-face velocities found are in the same range with values mentioned in literature 
(Gunnewiek, Hollands et al. 2002). The configurations used in this study are briefly presented in Table 1.

Table 1: Case studies and experimental setup configurations

\begin{tabular}{|c|c|c|c|}
\hline Experimental setup & $\begin{array}{c}\text { Reference case } \\
\text { (round perforation } \\
\text { Voltage 7.091V and } \\
\text { maximum velocity } \\
0.66 \mathrm{~m} / \mathrm{s} \text { ) }\end{array}$ & $\begin{array}{c}\text { Case 1 } \\
\text { (cross perforation } \\
\text { Voltage 7.091V } \\
\text { and maximum } \\
\text { velocity 0.64m/s) }\end{array}$ & $\begin{array}{c}\text { Case 2 } \\
\text { (cross perforation } \\
\text { Voltage 7.191V and } \\
\text { maximum velocity } \\
0.66 \mathrm{~m} / \mathrm{s} \text { ) }\end{array}$ \\
\hline $\begin{array}{c}\text { Flow measurements (PIV } \\
\text { and visualizations) }\end{array}$ & - & $\mathrm{X}$ & $\mathrm{X}$ \\
\hline $\begin{array}{c}\text { Temperature } \\
\text { measurements (Halide } \\
\text { lamps for Sun simulation) }\end{array}$ & $\mathrm{X}$ & $\mathrm{X}$ & $\mathrm{X}$ \\
\hline
\end{tabular}

A first experimental campaign consisted in PIV measurements (Figure 3) in the median plane of the box in the configuration Case 2 (same volumetric air flow for the two perforated panels). A CMOS Nano Sense MKII camera was used, with a maximum acquisition rate of 5 $\mathrm{kHz}$ and a maximum resolution of $512 \times 512$ pixels. Measurements consisted in the recording of series of pairs of images for frequencies between 100 and $300 \mathrm{~Hz}$. The light source was an infrared laser Nanopower with a power of $4 \mathrm{~W}$ and a wavelength of $795 \mathrm{~nm}$. The seeding particles were isothermal olive oil droplets from an atomizer. The images calibration gave a spatial resolution of $26.8 \mu \mathrm{m}$ per pixel which corresponds to a 40 x $40 \mathrm{~mm}^{2}$ field of view.

We considered a number of 1000 pairs of images which have been processed through an adaptive correlation algorithm with a multi-grid approach using window distortion and subpixel displacement of the windows. The airflow parameters were permanently monitored by a hot air anemometer, as it will be later described in the next section.

The purpose of this first experimental evaluation is to analyze the differences of the flow parameters for lobed and circular jets generated by the cladding perforations, in order to better understand the dynamics of the flow, which definitely contribute to an enhanced heat transfer. 
A second experimental campaign aimed the comparison between the baseline case with round perforations and the innovative cladding with lobed shaped perforations (Figure 4). Solar radiation was simulated using a Metal Halide Flood Light, a $500 \mathrm{~W}$ lightning level source, placed for these particular measurements at $45 \mathrm{~cm}$ distance from the cladding. This type of lamp can be an alternative of solar simulators because of its increased light efficacy of over $90 \mathrm{~lm} / \mathrm{W}$, good compromise in spectral characteristics, closely corresponding to sun light besides a long life time (more than 1000 hours) and relative inexpensive cost (Beeson 1978). A exhaust fan is used to force the air to pass through the perforated cladding. At this stage, the air heats up by a forced convective phenomenon, the heat being transferred from the metal to the fluid. Air velocity and temperature were permanently monitored at the outlet, were the air is exhausted from the box. Other velocity and temperature probes were placed in strategic points, for either control the conditions, either to obtain other results of the measurements.

The outlet airflow parameters rate were evaluated using a hot-film anemometer (TSI Velocicalc 9565) inside the outlet tube (point 3 in Figure 4c). The measured velocity in this point is considered a conventional maximum value from the velocity profile. The acquisition time step is 30 seconds for the hot film measurements.

The indoor temperature and cladding surface temperature were monitored by K-type thermo couples from Lutron. An infrared camera FLIR B620 was used to evaluate the surface temperature of the cladding.

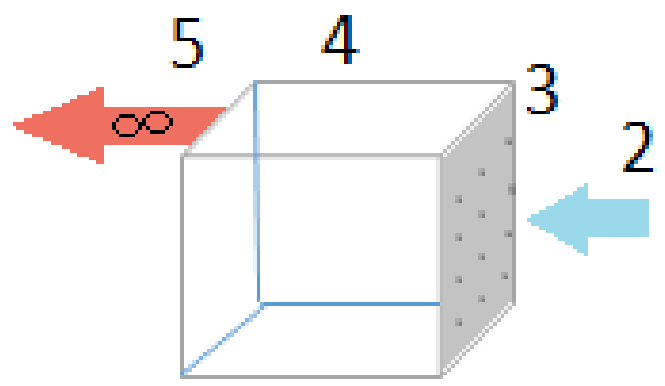



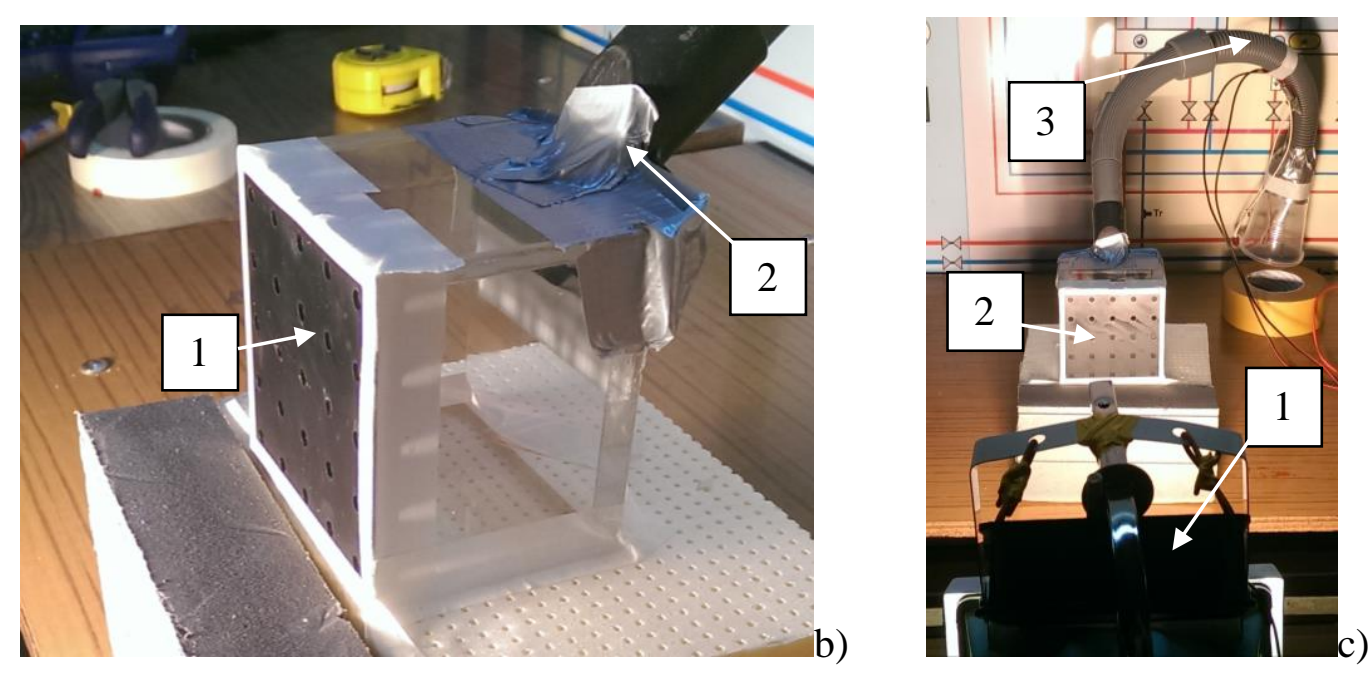

Figure 4: Experimental facility for air heating measurements: a) Schematic experimental setup: 1- Metal Halide lamp; 2- Exterior cold air; 3- Perforated metal cladding; 4Rectangular box; 5- Exhausted heated air by the fan; b) Detail of the box and the perforated cladding: 1- inlet; 2- outlet; c) Assembly of the functioning system: 1- halide lamp, 2- box, 3exhausting pipe- measuring point for temperature and velocity;

The purpose of this second part of this study is to compare the heat transfer and temperature increase in the case of the lobed jets, comparing with circular ones.

\section{RESULTS AND DISCUSSION}

We shall first present the results from the first experimental campaign, analysing the flow characteristics generated by the two types of perforated claddings using optical investigation methods.

Mean velocity fields from PIV measurements, in the median plane of the box, comprising two jets for each configuration, are presented in Figure 5. We can observe the differences in the flow field for the two geometries of the perforations. Generally, for very low velocities such as the one occurring in the case of an UTSW, the circular flow is highly unstable, and the mean field might require a huge amount of instantaneous velocity fields in order to obtain a representative result. From previous studies (Nastase, Meslem et al. 2008, Nastase and 
Meslem 2010), we know that the lobed orifice geometry induces particular well developed and vigorous streamwise vortices that play an important role in entrainment and mixing phenomena and thus in the stabilization of the jet flow (Figure 5c). Indeed, for the circular perforation it can be observed in Figure 5a that the two captured jets are unstable being influenced by recirculation zones inside the box. In Figure 5a, the recirculation zones can be seen at the following coordinates: $(X=7.5 ; Y=2.5),(X=7.5 ; Y=12.5),(X=7.5 ; Y=27.5)$, $(\mathrm{X}=10 ; \mathrm{Y}=32.5)$. This is not the case for the lobed cross shaped perforation where the mean flow is stable upon the considered image sampling interval resulting in well-defined air jets (Figure 5b).
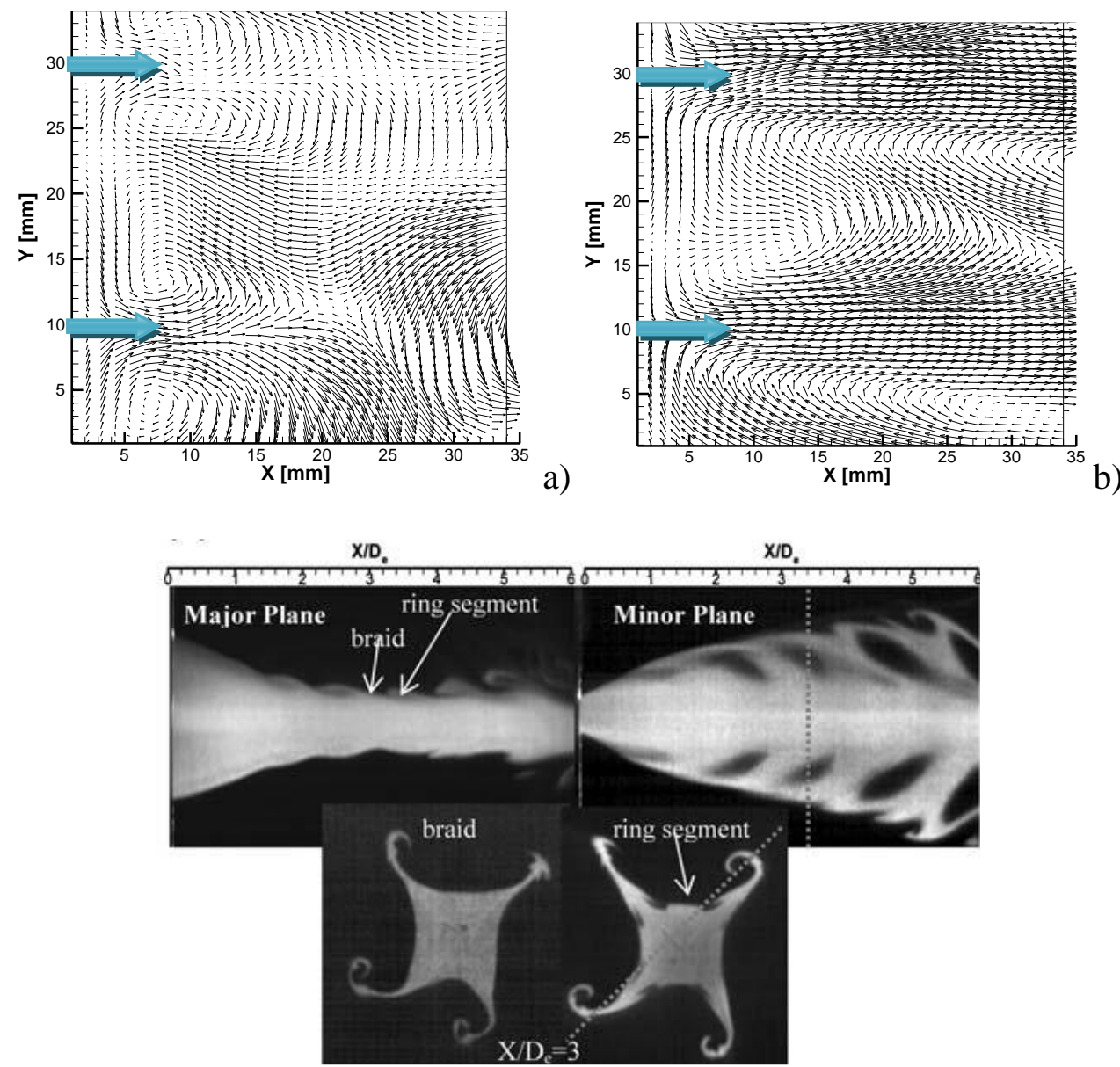

Figure 5: Longitudinal velocity fields (perforations indicated by blue arrows): a) and b) Detail of velocity fields as pointed with a red rectangle in Figure $3 \mathrm{~b}$ for round perforation(a) and lobed cross perforation(b); c) jet flow dynamics from (Nastase, Meslem et al. 2008) 
In the second part of the experiments, the thermal behavior of the same system was evaluated. We have measured the outlet temperature of the air at the exit of the box and the velocity inside the exhaust pipe. The obtained values of parameters, for the two geometries, are presented in Table 2 and Table 3 . We have obtained around $0.35 \mathrm{~m} / \mathrm{s}$ in each perforation, value in agreement with literature and the first part of the experiment (Leon and Kumar 2007).

Table 2. Values obtained during the measurements with the round perforation cladding

\begin{tabular}{|c|c|c|c|c|c|c|c|c|c|c|}
\hline $\boldsymbol{V}_{\text {air-tube max }}$ & $\boldsymbol{V}_{\text {air- tube mean }}$ & $\boldsymbol{Q}_{\text {tube }}$ & $\boldsymbol{Q}_{\text {tube }}$ & $\boldsymbol{T}_{\text {air-tube }}$ & $\boldsymbol{T}_{\text {air }}$ & $\Delta \boldsymbol{t}$ mean & $\boldsymbol{T}_{\text {surf }}$ & $\boldsymbol{P}_{\text {surf }}$ & $\boldsymbol{P}$ & $\boldsymbol{V}_{\text {perf }}$ \\
\hline $\mathbf{m} / \mathbf{s}$ & $\mathbf{m} / \mathbf{s}$ & $\mathbf{m}^{\mathbf{3}} / \mathbf{h} / \mathbf{m}^{\mathbf{2}}$ & $\boldsymbol{m}^{\mathbf{3}} / \mathbf{h}$ & ${ }^{\circ} \mathbf{C}$ & ${ }^{\circ} \mathbf{C}$ & ${ }^{\circ} \mathbf{C}$ & ${ }^{\circ} \mathbf{C}$ & $\boldsymbol{W}$ & $\mathbf{W} / \mathbf{m}^{\mathbf{2}}$ & $\mathbf{m} / \mathbf{s}$ \\
\hline 0.66 & 0.46 & 63.19 & 0.63 & 23.4 & 20.1 & 3.30 & 35.2 & 0.695 & 70 & 0.36 \\
\hline 0.66 & 0.46 & 63.19 & 0.63 & 24.2 & 21.6 & 2.60 & 39.9 & 0.548 & 55 & 0.36 \\
\hline 0.66 & 0.46 & 63.19 & 0.63 & 24.4 & 21.4 & 3.00 & 40.1 & 0.632 & 63 & 0.36 \\
\hline 0.66 & 0.46 & 63.19 & 0.63 & 24.4 & 21.4 & 3.00 & 40.4 & 0.632 & 63 & 0.36 \\
\hline
\end{tabular}

Table 3. Values obtained during the measurements with the cross perforation cladding for both cases

\begin{tabular}{|c|c|c|c|c|c|c|c|c|c|c|c|}
\hline & $V_{\text {air- tube max }}$ & $V_{\text {air-tube mean }}$ & $Q_{\text {tube }}$ & $Q_{\text {tube }}$ & $T_{\text {air-tube }}$ & $T_{\text {air }}$ & $\Delta t$ mean & $T_{\text {surf }}$ & $\boldsymbol{P}_{\text {surf }}$ & $P$ & $V_{\text {perf }}$ \\
\hline & $\mathrm{m} / \mathrm{s}$ & $\mathrm{m} / \mathrm{s}$ & $m^{3} / \mathrm{h} / \mathrm{m}^{2}$ & $m^{3} / h$ & ${ }^{\circ} \mathrm{C}$ & ${ }^{\circ} \mathrm{C}$ & ${ }^{\circ} \mathrm{C}$ & ${ }^{\circ} \mathrm{C}$ & $w$ & $w / m^{2}$ & $\mathrm{~m} / \mathrm{s}$ \\
\hline \multirow{5}{*}{ Case 1} & 0.64 & 0.45 & 61.28 & 0.61 & 24.4 & 21.3 & 3.10 & 36.2 & 0.633 & 63 & 0.35 \\
\hline & 0.64 & 0.45 & 61.28 & 0.61 & 24.52 & 21 & 3.52 & 37.1 & 0.719 & 72 & 0.35 \\
\hline & 0.64 & 0.45 & 61.28 & 0.61 & 24.58 & 20.9 & 3.68 & 38 & 0.752 & 75 & 0.35 \\
\hline & 0.64 & 0.45 & 61.28 & 0.61 & 24.48 & 20.7 & 3.78 & 38.1 & 0.772 & 77 & 0.35 \\
\hline & 0.64 & 0.45 & 61.28 & 0.61 & 24.5 & 20.4 & 4.10 & 38.2 & 0.837 & 84 & 0.35 \\
\hline \multirow{3}{*}{ Case 2} & 0.66 & 0.46 & 63.19 & 0.63 & 24.5 & 20.3 & 4.20 & 37.9 & 0.885 & 88 & 0.36 \\
\hline & 0.66 & 0.46 & 63.19 & 0.63 & 24.5 & 20.3 & 4.20 & 37.2 & 0.885 & 88 & 0.36 \\
\hline & 0.66 & 0.46 & 63.19 & 0.63 & 24.42 & 20.2 & 4.22 & 37.1 & 0.889 & 89 & 0.36 \\
\hline
\end{tabular}

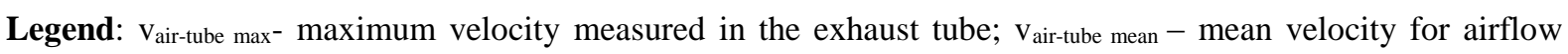
calculation; $\mathrm{Q}_{\text {tube- }}$ airflow; $\mathrm{T}_{\text {air-tube }}-$ air temperature measured in the exhaust tube; $\mathrm{T}_{\text {air }}-$ ambient air temperature; $\Delta \mathrm{t}$ mean cross/round- temperature difference between the exhaust air temperature and ambient air temperature; $\mathrm{T}_{\text {surf }}$-temperature measured on the metal cladding; $\mathrm{P}_{\text {surf }}$-heat transfer for a given airflow and temperature difference calculated with the mass flow rate, air specific heat and temperature difference; $\mathrm{P}-$ heat transfer for a given airflow and temperature difference integrated on a square meter; $v_{\text {perf }}$-calculated mean velocity at the perforation level;

We have shown in Figure 6 the evolution of the ambient temperature in comparison with the exhaust temperature measured at outlet for the Reference case and Case 2, in order to compare the results for the same airflow value. In fact, the difference of temperature is the main parameter in the evaluation of heat transfer of such devices. We can see clearly that the lobed perforated cladding performs better, since the $\Delta t$ is higher for the entire measuring 
period.
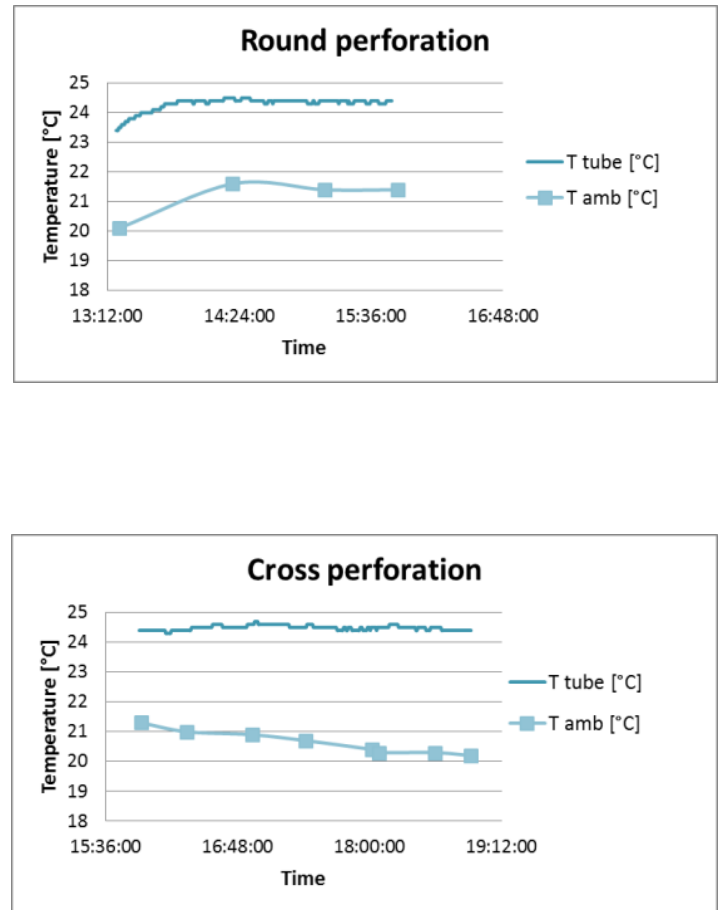

a)

b)

Figure 6: Evolution of ambient temperature and outlet temperature over the test period a)

Round perforation (Reference case); b) Cross perforation (Case 2)

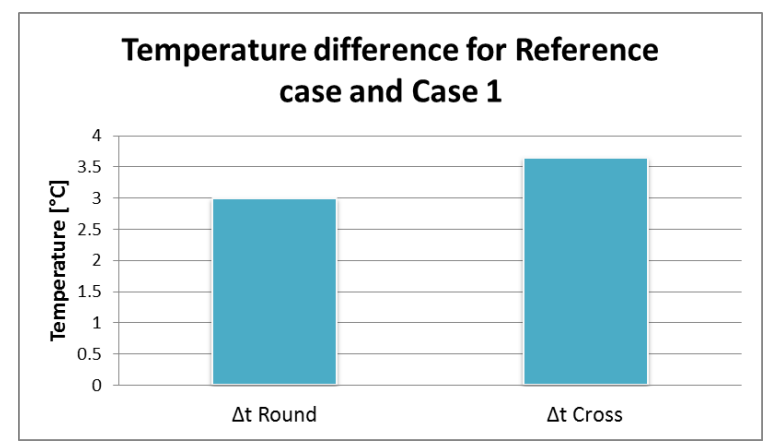




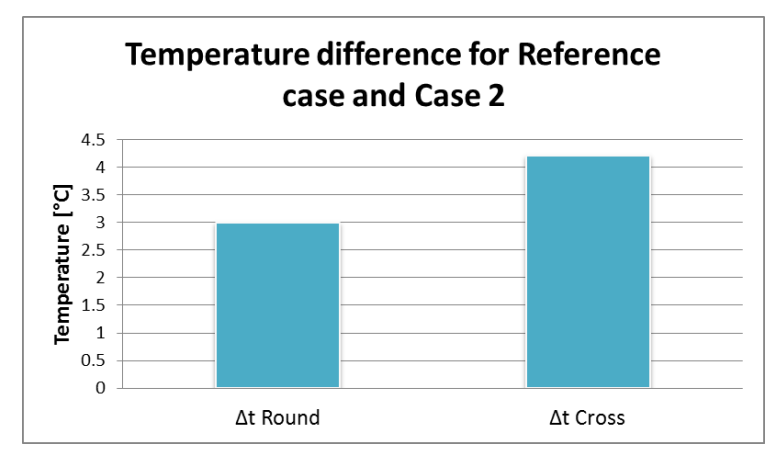

b)

Figure 7: Comparison of obtained mean temperature difference: a) Mean temperature difference for Reference case versus Case 1 (same voltage for the fan); b) Reference case versus Case 2 (same maximum velocity)

This difference is shown better in Figure 7. In the first figure we have compared the difference of temperature for round perforation in Reference case and cross perforation in Case 1 (in the case where we kept the voltage constant, at $7.091 \mathrm{~V}$ ). In the second figure we represented the temperature difference for Reference case and Case 2 (having the same outlet velocity, or, in other words, same airflow). For both cases we can observe clearly that the cross perforated cladding induces a higher transfer rate, conclusion also underlined in Figure 8 , with more than $25 \mathrm{~W} / \mathrm{m}^{2}$ difference between the round case (Reference case) and lobed case(Case 2).

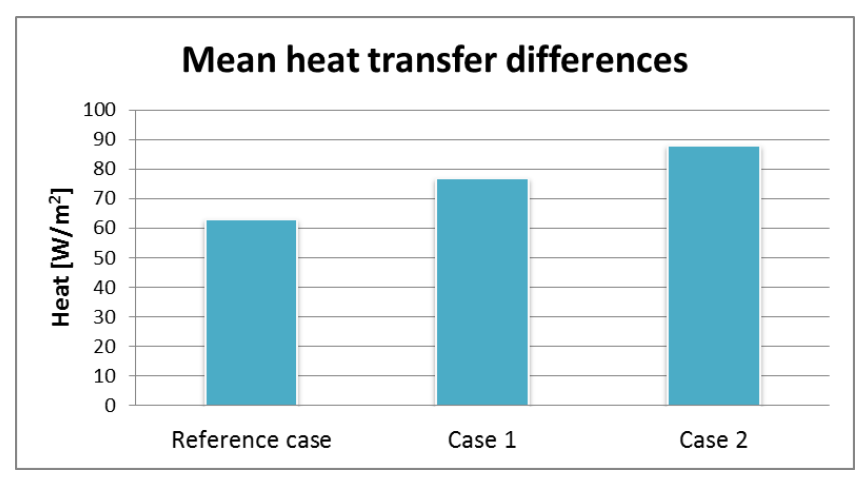


Figure 8: Mean heat transfer for 1 square meter: comparison of the thermal behavior for Reference case, Case 1 and Case 2
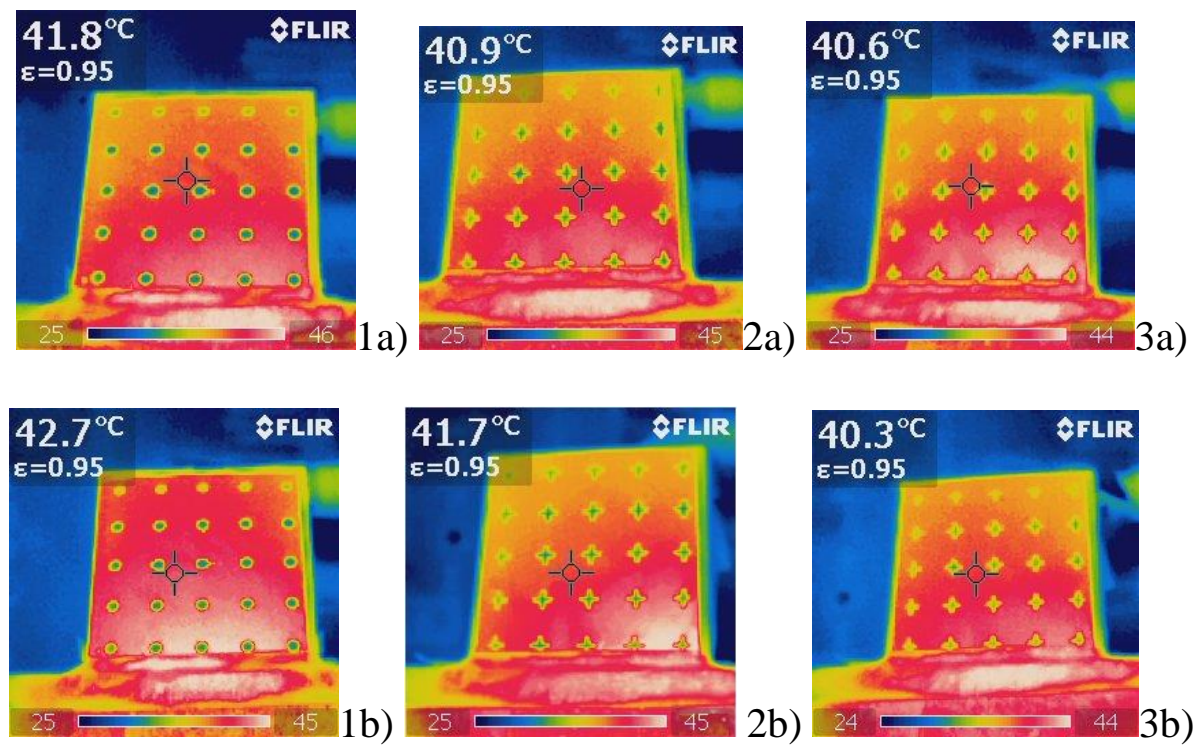

Figure 9: IR temperature fields: 1) Reference case a) beginning of the heating; b) end: 60 minutes later; 2) Case 1 a) beginning of the heating; b) end: 60 minutes later; 3) Case 2 a) beginning of the heating; b) end: 60 minutes later;

The IR images prove the heat transfer, since the cladding is better cooled for the cross case (Case 1 and 2): we can see in Figure 9-1b) the temperature of the metal panel is higher, even in comparison with Case 1, or Figure 9-2b), where we have lower airflow. For each measurement a stabilization period of 60 minutes was applied in order to obtain the actual value of the temperature in the considered case.

For this setup, we can see in Figure 10 the heat transfer increase, calculated in percentages for the cross perforation (Case 2), is higher with almost $40 \%$ in comparison with the classical system (Reference case), for the same airflow conditions (same velocity). 


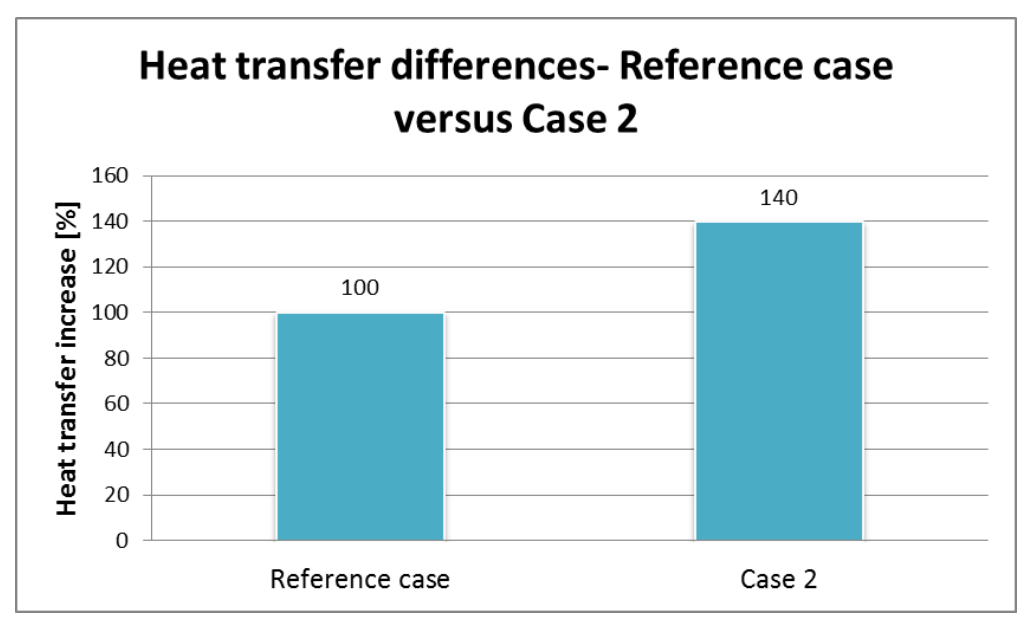

Figure 10: Heat transfer increase for Reference case and Case 2 (the same airflow) in percentages

\section{CONCLUSIONS}

The study evaluated the energy efficiency of two types of unglazed transpired solar collector (UTSW) by experimental means. The physical model used shows good results in agreement with literature. The PIV measurements show a different behaviour of the flow inside the ventilated solar wall as a function of the cladding's perforation. The streamwise vortices induced by the lobed shaped perforation help in the stabilization of the jet flows inside the ventilated cavity. The more complex dynamics of the lobed flows results in a better heat transfer rate. Indeed, the comparison of a conventional UTSW with a new geometry with innovative perforation leads to interesting results, with almost $40 \%$ increase in heat transfer between the perforated cladding and the exhausted airflow. This is a very promising finding in the context of the present literature where few studies regarding the influence of the perforation's geometry are present. These phenomena still need to be further investigated. 


\section{ACKNOWLEDGEMENT}

This work was supported by the grants of the Romanian National Authority for Scientific Research, CNCS - UEFISCDI, project numbers PN-II-RU-PD-2012-3-0144 and PN-II-IDPCE-2011-3-0835.

\section{REFERENCES}

Al-Shaalan, A. M. (2012). "EER Improvement for Room Air-Conditioners in Saudi Arabia." Energy and Power Engineering Vol.04No.06: 8.

Arulanandam, S. J., K. G. T. Hollands and E. Brundrett (1999). "A CFD heat transfer analysis of the transpired solar collector under no-wind conditions." Solar Energy 67(1-3): 93-100.

Beeson, E. J. G. (1978). "The CSI lamp as a source of radiation for solar simulation." Lighting Research and Technology 10(3): 164-166.

Belusko, M., W. Saman and F. Bruno (2008). "Performance of jet impingement in unglazed air collectors." Solar Energy 82(5): 389-398.

Cordeau, S. and S. Barrington (2011). "Performance of unglazed solar ventilation air preheaters for broiler barns." Solar Energy 85(7): 1418-1429.

Energy, E. P. a. C. o. (2002). The Directive on the energy performance of buildings 2002/91/EC.

Gunnewiek, L. H., E. Brundrett and K. G. T. Hollands (1996). "Flow distribution in unglazed transpired plate solar air heaters of large area." Solar Energy 58(4-6): 227-237.

Gunnewiek, L. H., K. G. T. Hollands and E. Brundrett (2002). "Effect of wind on flow distribution in unglazed transpired-plate collectors." Solar Energy 72(4): 317-325.

Hami, K., B. Draoui and O. Hami (2012). "The thermal performances of a solar wall." Energy 39(1): 11-16.

Hollick, J. C. (1994). "Unglazed solar wall air heaters." Renewable Energy 5(1-4): 415-421. Hollick, J. C. (1998). "Solar cogeneration panels." Renewable Energy 15(1-4): 195-200.

IEA. (2005). "Solar's Untapped Potential." from http://www.ieashc.org/solarenergy/potential.htm.

IEA (2007). Renewables for heating and cooling: untapped potential. France: OECD/IEA; IEA (2007). "World energy outlook 2007: China and India insights. France: OECD/IEA;:"

IEA (2008). Worldwide trends in energy use and efficiency: key insights from IEA indicator analysis. France: OECD/IEA.

IEA (2013). Transition to Sustainable Buildings - Strategies and Opportunities to 2050. I. E. Agency.

Konttinen, P., T. Salo and P. D. Lund (2005). "Degradation of unglazed rough graphitealuminium solar absorber surfaces in simulated acid and neutral rain." Solar Energy 78(1): 41-48.

Kumar, P. and L. Morawska (2013). "Energy-Pollution nexus for urban buildings." Environmental Science \& Technology 47: 7591-7592. 
Kumar, S. and S. C. Mullick (2010). "Wind heat transfer coefficient in solar collectors in outdoor conditions." Solar Energy 84(6): 956-963.

Leon, M. A. and S. Kumar (2007). "Mathematical modeling and thermal performance analysis of unglazed transpired solar collectors." Solar Energy 81(1): 62-75.

Molineaux, B., B. Lachal and O. Guisan (1994). "Thermal analysis of five unglazed solar collector systems for the heating of outdoor swimming pools." Solar Energy 53(1): 27-32.

Nábìlek, B., E. Kiran, F. Türksoy and A. Yazar (1999). "Performance of an unglazed textileplastic solar absorber." Renewable Energy 16(1-4): 635-638.

Nastase, I. and A. Meslem (2010). "Vortex Dynamics and mass entrainement in turbulent lobed jets with and without lobe deflection angles." Experiments in Fluids 48(4): 693-714. Nastase, I., A. Meslem and P. Gervais (2008). "Primary and secondary vortical structures contribution in the entrainement of low Reynolds number jet flows." Experiments in Fluids 44(6): 1027-1033.

Reichl, C., K. Kramer, C. Thoma, P. Benovsky and T. Lemée (2015). "Comparison of modelled heat transfer and fluid dynamics of a flat plate solar air heating collector towards experimental data." Solar Energy 120: 450-463.

Sopian, K., M. Syahri, S. Abdullah, M. Y. Othman and B. Yatim (2004). "Performance of a non-metallic unglazed solar water heater with integrated storage system." Renewable Energy 29(9): 1421-1430.

UNEP (2007). BUILDINGS AND CLIMATE CHANGE- Status, Challenges and Opportunities. United Nations Environment Programme, European Union.

Van Decker, G. W. E., K. G. T. Hollands and A. P. Brunger (2001). "Heat-exchange relations for unglazed transpired solar collectors with circular holes on a square or triangular pitch." Solar Energy 71(1): 33-45. 